\title{
Study on the Development of Agricultural Tourism around Mengshan Mountain
}

\author{
Zhaoyun Li \\ Department of State Owned Assets and Laboratory Equipment in Linyi University \\ Linyi, China 276000
}

\begin{abstract}
The development zone of agricultural tourism around Mengshan mountain is located in Linyi City, Shandong Province. As the national famous old liberated area, it has long history of agricultural development and rich agricultural tourism resources. Under the scientific guidance of the local government, the area around Mengshan mountain makes full use of the local natural resources and conditions. Its center development is landscape and famous scenery in Mengshan mountain. It drives common development of Mengyin, Pingyi, Feixian, Yi'nan and other areas and forms the characteristic industry of agricultural tourism in area around Mengshan mountain which featured in fruit industry, Chinese herbal medicine industry and edible fungus planting industry. Agricultural tourism around Mengshan mountain has developed rapidly. During the process, it also arises some problems like low intensivism, lagging concept of development and lacking characteristic supported industries. In this regard, according to the goal of promoting sustainable development in area around Mengshan mountain, we propose the development strategies of expanding market, changing concept and modeling brand to drive the development of whole agricultural tourism in area around Mengshan mountain.
\end{abstract}

Keywords-Mengshan mountain; agriculture; tourism; development

\section{INTRODUCTION}

With the continuous improvement of urbanization level in China, a large number of people swarm into the city, occupying some city's limited living space and public resources, causing crowded traffic and other unfavorable factors, which bring living enormous pressure to the urban inhabitants. Urban inhabitants are eager to relax and relieve stress through the way of outdoor tourism. For this reason, a kind of tourism consumption patterns - agricultural tourism - that caters today's society psychological need of returning to nature is emerged. The agricultural tourism is a new industrial pattern combined agricultural resources with tourism. In rural areas where rely on local agricultural resources, recreational projects are designed according to the needs of tourists. Tourists experience agricultural activities and enjoy the fun of returning to nature by participating in tourism activities. At present, China's economic development enters a new normal. The government adjusts the industrial structure actively and develops green low-carbon industry vigorously. Tourism as a new industry is in line with the development trend of modern green economy. In the future, rural areas will be one of the key areas of tourism development, and agricultural tourism will promote the economic development transformation of rural areas to achieve common prosperity.

\section{THE DEVELOPMENT SitUATION OF AgRICULTURAL TOURISM IN AREA AROUND MENGSHAN MOUNTAIN}

The development zone of agricultural tourism around Mengshan mountain is located in Linyi City of Shandong Province and mainly distributed in Mengyin, Pingyi, Feixian and Yinan. Tourist area around Mengshan mountain relay on the unique natural advantages to develop healthy agriculture mainly, and then make industrial brand of characteristic agricultural tourism around Mengshan mountain. In recent years, the core competitiveness of promoting modern agriculture development in Linyi city is brand agriculture. We develop modern green ecological agriculture vigorously. On the one hand, it promotes the development of agricultural modernization, and on the other hand, it improves the quality of ecological environment and optimizes the conditions of agricultural tourism development. In order to adapt to modern trend of tourism development and satisfy the needs of masses of consumers, we remold and upgrade the traditional agricultural development model in area around Mengshan mountain, and mainly make characteristic ecoagriculture tourism brand. The development of tourism promotes air pollution, water pollution, garbage pollution and other environmental problems to be solved effectively, realizes development of agricultural tourism in area around Mengshan mountain and realizes improvement of ecological environment.

The agricultural tourism in area around Mengshan mountain has increased considerably since beginning to develop the agricultural tourism in 2001. The tourism income and the number of tourists in 2016 have increased by 4.3 billion yuan and 5.87 million than 2012. The tourism income and the number of tourists in 2016 have risen by $273 \%$ and $161 \%$ than 2012 . Now, the agricultural tourism in area around Mengshan mountain has a national agricultural tourism demonstration site: Feixian Shilin Pear Town tourist area. And six tourist areas are also provincial agricultural tourism demonstration sites. The development of agricultural tourism in area around Mengshan mountain has a certain foundation and has played the leading role in the development of tourism in Linyi. It makes the social and economic status of the tourism in Linyi increase year by year, of which the proportion of tourism income increases from 
four percentage points to eight percentage points. The tourism has become a pillar industry in Linyi.

\section{The Development Model of Agricultural TOURISM IN AREA AROUND MENGSHAN MOUNTAIN}

\section{A. Use Fruitwood Garden to Develop Sightseeing Tourism}

In recent years, Linyi City has extensively carried out the work of returning land for farming to forestry and planted large quantities of fruitwood economic forest to improve the agricultural economic efficiency and the ecological environment. The concentrated areas are Shilin Pear Town and Peony Hickory Demonstration Garden in Feixian, Pingyi Baili Guoxiang garden and so on. There have been many non-grain villages, non-grain towns, and some well-known grape village, ginkgo village, apple village, pear village and so on. In order to enhance the enjoyment and participation of landscape sightseeing tourism, these places generally set up tour routes in the park, ornament park with constructed various attractions or opusculum, launch different tourism projects in different seasons such as spring country walk, admiring flower, fruit picking and so on.

\section{B. Use Rural Houses to Carry Out Ethnic Tourism}

Since the mid-1990s, the tourism industry in Shandong Province had carried out ethnic tourism characterized by the tourists eating, living and laboring together with farmers. In recent years, Linyi City has also carried out ethnic tourism characterized by rural family, such as Pingyi nine shed village and Bianqiao Kuei Ku-tzu village. Nine shed village develops tourism through transforming old village. Kuei Kutzu village is located in the Dawa tourist area. In recent years, farmers have planted fruit trees around their houses and used spare rooms to open family restaurants and hotels. These attract tourists to visit farm landscape, eat farm food and live in rural housing. Kuei Ku-tzu village has developed a number of industries and bringed annual output value of 2.53 million, which greatly increase farmers' income.

C. Construct High-tech Demonstration Park and Develope Agricultural Science and Technology Tourism, Such as Peony Hickory Demonstration Garden in Feixian and So On

Its main practice is to introduce domestic and foreign varieties and high-tech of planting, so the fruit trees, flowers, vegetables and other plants in park not only have edible value, but also have ornamental value. The park is divided into a number of areas, such as nursery area, cultivation area and greenhouse area. Fruit trees and flowers are divided into different planting areas that have their own characteristics, so visitors feel very fresh.

D. Construct Green Tourism Area, Tourism Zone and Carry Out Eco-tourism, Such as Pingyi Tianbao Pear Town Agricultural Tourism Area, Mengyin Village Fruit Tourism Belt and So On

It has two prominent features. Firstly, the tourist areas and zones are planed by experts in tourism, gardens and other domains who are hired specially; Secondly, some kind of plant is regarded as the main feature in the area. For example, the main features in Mengyin village fruit tourism belt are Mengshan mountain scenery and apple orchard.

\section{THE PROBLEMS OF DEVELOPMENT OF} Agricultural Tourism AROUND MENGShan Mountain

\section{A. Intensive Degree Is not High}

The brand influence of agricultural tourism in area around Mengshan mountain is not big enough. The tourist market is mainly distributed in the surrounding areas of Linyi. The main business model of local agricultural tourism is farm stay. Begin with the initial nostalgia of urban human, farm stay gradually evolved into an independent tourism mode with the characteristics of eco-tourism and cultural tourism. The farm stay's managers renovate the family, attract tourists on the basis of the original natural resources of the region, and let the tourists experience the rural life in the process of tourism. Although the development level of farm stay in area around Mengshan mountain has been improved, there are still many problems in the process of its operation, mainly in: lacking unified standards in the development of the industry, using family-style business model more, scattered layout, forming scale management with difficult. These are not conducive to brand building.

\section{B. Lack of Characteristic Supporting Industry}

Agricultural tourism is conducive to the economic development of rural areas, and can promote the adjustment of industrial structure in rural areas. In the management process of agricultural tourism in area around Mengshan mountain, most tourism managers are mostly affected by the market. They follow the trend of the development of tourism projects blindly, and ignore their own business advantages. Most of the tourism projects on the market of agricultural tourism in area around Mengshan mountain are lacking creativity and type. Agricultural tourism should make full use of local tourism resources and develop tourism with the help of specific natural, geographical and cultural resources to cater to today's tourism market trends.

\section{The Concept of Development Is Backward}

The ecological environment plays an important role in the development of agricultural tourism. The development of tourism has caused different degree of damage to the local ecological environment. In the process of tourism development in area around Mengshan mountain, there are some serious problems such as unreasonable development of tourism projects, scenic supervision system that not in place and other serious problems, resulting in emerging a serious damage to ecological environment and carrying capacity of scenic spot declining in the process of the development of local agricultural tourism. If these problems are not resolved, they will become obstacle in the future development of agricultural tourism in area around Mengshan mountain.

\section{The StRategies of DeVElopMENT OF Agricultural TOURISM AROUND MENGShan Mountain}

\section{A. To Increase Financial Support}

In the process of development of agricultural tourism around Mengshan mountain, the government should always 
play a good macro-regulator role. The lack of funds often hinders the development of agricultural tourism, and further affects the extension of the tourism industry chain. There are two phenomena in the agricultural tourism market: tourism enterprises especially small and medium-sized enterprises have difficulties in financing, and farmers don't want to put money into the tourism industry. In order to solve these problem, the government should support the local tourism enterprises, increase investment in tourism enterprises, reduce lending rate for agricultural tourism enterprise, broaden the financing channels for small and medium-sized tourism enterprises, and carry out propaganda and education to change farmers' investment concept.

\section{B. To Improve the Agricultural Tourism Development Mechanism}

The development zone of agricultural tourism around Mengshan mountain covers a wide range. In order to develop agricultural tourism better and more orderly, it is necessary to do responsible subarea. First of all, we should clear and definite the specialized functional departments to be responsible for agricultural tourism management, improve agricultural tourism policies and regulations, formulate "the Measures for the Administration of Agricultural Tourism Services in Area around Mengshan mountain", and then ensure that the work of agricultural tourism is carried out within the framework permitted by laws and regulations. For the agricultural tourism management, we should implement access system and set up strict examination and approval procedure. In particular, for some important agricultural tourism development projects such as: farm stay, pleasure ground, tourism companies and so on, we should do a strict qualification examination before allowing them to enter the market, and clear and definite the main responsibility to ensure the healthy development of tourism market.

\section{To Formulate a Reasonable Development Plan}

The healthy development of tourism can't be separated from the laws and regulations. The local government should improve the local tourism development policies and regulations, deal timely and accurately with safety accidents that may occur on tourists in the tourism process, feed back the results to tourists timely, and satisfy tourists. For the unfair competition in the tourism market and the destruction of the environment, the government should increase the intensity of punishment and find out who is to blame. The focus of making development planning is that the design of the area should be integrated with the local natural conditions rather than unilateral pursue of economic benefits through scale aggregation effect. Its starting point and the foothold is the development and protection of tourism resources. Reasonable tourism development planning should proceed from the sustainable development of tourism resources, and protect the integrity of the ecological environment.

\section{To Enrich the Tourism Products and Connotation}

Area around Mengshan mountain is a typical characteristic agriculture demonstration zone. In the process of upgrading products in local areas, you can enrich the connotation of the product and launch the main characteristics of local tourism products to satisfy tourists' shopping needs in process of travel. Enriching the connotation of tourism products not only can lengthen the agricultural tourism industry chain, but also can increase the added value of tourism products. Products of agricultural tourism in area around Mengshan mountain are still in the initial stage of processing and sales. Without deep processing, the economic value of tourism products is low. How to enrich the regional rural tourism products and create the unique regional characteristics of tourism industry, which relate to the long-term development of agricultural tourism.

\section{E. To Build a Complete Tourism Service Facilities}

The development of agricultural tourism in the area around Mengshan mountain should first clear the goal of improving tourism service facilities, focusing on strengthening construction on aspects of " eating, living, walking, travelling, shopping, entertainment". The aspect of eating: should regulate the operation of farm stay, establish the hotels which have modern tourism characteristics, and promote local special snacks. The aspect of eating living: should learn from the development model of tourism in Yunnan, promote the development of Home Stay tourism, increase financial subsidies , and encourage local farmers to join the development team of Home Stay tourism . The aspect of walking: should plan the tourist routes reasonably and strengthen the construction of the service network around the traffic trunk line. The aspect of travelling: should design tourism projects and routes according to the characteristics of tourism destination and add networks to sell the scenic spot ticket. The aspect of shopping: should build tourism products shopping site in scenic spot, regulate the price of tourism products and crack down on the unfair competition of high prices rigorously. The aspect of entertainment: the development of tourism projects should have local characteristics to meet the needs of different tourists.

\section{F. To Improve the Idea of Development}

In the future development planning of agricultural tourism in area around Mengshan mountain, we should establish a brand awareness, highlight the position of "agricultural eco-tourism", use the brand to promote tourism development, enhance the local tourism product managers' brand awareness and form local tourism development scale effect to promote tourism development. The local government should increase the publicity efforts of the vast rural areas, guide Mengshan mountain local farmers to change the traditional farming habits of depending on the weather and develop the new agricultural tourism model vigorously. Local residents should actively respond to the call of government, keep eyes on, try to learn the professional knowledge of tourism management, and engage in agricultural tourism industry management.

\section{CONCLUSION}

With the development of economy, agricultural tourism will become an important part of economy in area around Mengshan mountain in the future. Linyi municipal government should scientifically guide the area around Mengshan mountain to make full use of the local natural 
resources conditions, regard Mengshan mountain landscape and famous scenery as development center, promote the common development of the surrounding areas, form the characteristic industry of agricultural tourism in area around Mengshan mountain which featured in fruit industry, Chinese herbal medicine industry and edible fungus planting industry. In order to make a theoretical contribution to the development of local tourism, this paper puts forward some suggestions for the problems in the development of the agricultural tourism around Mengshan mountain. This paper lacks objectivity and not comprehensive enough in data collection. I hope the following research can be more objective and comprehensive.

\section{REFERENCES}

[1] Liu Jiaming, Yang Xinjun. Research on sustainable tourism development and planning in ecotourism destinations [J]. Journal of natural resources, 1999, Vol.14 No.1: p79 p83.

[2] Zhang Yu, YANG Xiao-xia. A study review on overseas agritourism [J]. Human geography, 2011, Vol.26.No.5:p15 p23.

[3] George H. Agritourism enterprises on your farm or ranch: where to start [Z]. ANR Publication, 8334, 2008. p1 p6.

[4] Carpio C E, Wohlgenant M K, Boonsaeng T. The demand for agritourism in the United States [J]. Journal of Agricultural and Resource Economics, 2008, 33(2): p254 p269.

[5] Xiedong. Analysis on Linyi agricultural tourism status and research on development tactics [D]. China Agricultural University, Beijing, 2005.

[6] Guohui. Research on rural tourism product planning in Yimeng Mountainous Area [D]. Shandong Normal University, Jinan, 2014.

[7] Wu Xiangfeng. Study on Evaluation of ecotourism resources and environmental capacity of Mengshan Mountain in Shandong [D]. Shandong Normal University, Jinan, 2011. 